\title{
Safety Study of Photodynamic Therapy Using Talaporfin Sodium in the Pancreas and Surrounding Tissues in the Syrian Golden Hamster
}

\author{
Johannes Wittmann, ${ }^{1}$ Matthew T. Huggett, ${ }^{2}$ Stephen G. Bown, ${ }^{1}$ and Stephen P. Pereira ${ }^{2}$ \\ ${ }^{1}$ National Medical Laser Centre, Division of Surgery and Interventional Science, \\ University College London Medical School, London, UK \\ ${ }^{2}$ UCL Institute for Liver and Digestive Health, University College London Medical School, London, UK
}

Correspondence should be addressed to Stephen P. Pereira; stephen.pereira@ucl.ac.uk

Received 5 November 2013; Accepted 4 January 2014; Published 25 February 2014

Academic Editor: Victor Loschenov

Copyright (C) 2014 Johannes Wittmann et al. This is an open access article distributed under the Creative Commons Attribution License, which permits unrestricted use, distribution, and reproduction in any medium, provided the original work is properly cited.

\begin{abstract}
Aim. To assess the safety of photodynamic therapy (PDT) using talaporfin sodium on the pancreas and surrounding organs in normal hamsters. Methods. Fluorescence microscopy documented talaporfin levels in liver, duodenum, and pancreas up to 24 hours after photosensitisation. Lesion size in liver 3 days after PDT ( $50 \mathrm{~J}, 5 \mathrm{mg} / \mathrm{kg}$, variable drug-light interval (DLI)) was documented to optimise the DLI. Using optimum DLI, pancreas and surrounding organs were treated with laser fibre touching the surface and animals were killed at 3 or 21 days. Results. Peak fluorescence was seen in duodenum and pancreas at 15 mins (second lower peak at 2 hours). Liver fluorescence was consistently high (peak 1 hour) until after 4 hours. Optimum DLI was seen at 15 minutes. The pancreas was relatively resistant to direct PDT injury (small lesions at high doses) but surrounding stomach, duodenum, and liver were more susceptible with evidence of adhesions and full thickness damage (localised peritonitis and duodenal perforation at highest doses). Conclusion. The safety profile is similar to PDT with longer acting photosensitisers. The pancreas appears safe to treat, but care is required to avoid high light doses to the intestinal tract, particularly the duodenum.
\end{abstract}

\section{Introduction}

In the UK approximately 8000 people are diagnosed with pancreatic adenocarcinoma each year $[1,2]$. Surgical resection is the only chance of cure and is only possible in a minority of subjects. Even after resection, the median survival is only $10-20$ months and only $12-35 \%$ of resected patients survive five years or more [3-6]. Palliative chemotherapy can improve both quality of life and survival in advanced disease [7-10], but overall, the long-term prognosis of the disease is poor with a one-year survival rate of 15-39\% [11-16]. These dismal results stimulated the search for a minimally invasive treatment capable of local destruction of tumour tissue with low morbidity that might have a place in the treatment of unresectable disease.

Photodynamic therapy (PDT) for pancreatic cancer was first described in 2002 [17]. This showed that image guided, interstitial PDT using the photosensitiser mTHPC (Foscan) could produce localised tumour necrosis with low morbidity, although the prolonged skin photosensitivity associated with mTHPC limited its acceptability for patients. This stimulated the search for shorter acting photosensitisers, with less potential photosensitivity.

Talaporfin sodium (LS11, Laserphyrin, mono-L-aspartyl chlorin; Light Sciences Corporation, Snoqualmie, WA, USA) is a chlorophyll and L-aspartic acid derived, pure photosensitiser codeveloped by Meiji Seika and Nippon Petrochemicals. The expected 1-2 week cutaneous photosensitivity following talaporfin administration is considerably shorter than that associated with other commonly used agents like porfimer sodium and mTHPC $[18,19]$. In 2004, talaporfin was approved in Japan for PDT for early stage non-smallcell lung cancer [20]. The drug is mainly confined to the vasculature during the first hour after intravenous injection 
and Phase II clinical trials using talaporfin sodium for palliation of colorectal liver metastases have been completed with minimal toxicity using drug light intervals of 15-60 minutes $[18,21]$.

Animal studies have established the safety and potential efficacy of PDT for pancreatic cancer using a variety of photosensitisers including mTHPC, dihaematoporphyrin ether (DHE), and 5-ALA [22-24]. However, the effects and safety of talaporfin PDT on the normal pancreas and surrounding abdominal organs have not been studied. This study reports safety data using the normal female Syrian golden hamster.

\section{Methods}

The study was undertaken on normal mature, female Syrian golden hamsters, 90-120 g in weight. Approval was obtained from the local ethics committee and performed under UK Home Office licenses issued under "The Protection for Animals (Scientific Procedures) Act, 1986”. All animals were cared for within university animal facilities and published guidelines on the care and treatment of laboratory animals were followed. All procedures were carried out under general anaesthesia, initiated by an intraperitoneal injection of Hypnorm (fentanyl and fluanisone, Janssen Pharmaceuticals), midazolam $5 \mathrm{mg} / \mathrm{mL}$ (Roche Pharmaceuticals), and sterile water in a 1:1:2 mixture; and maintained by inhalational halothane (ICI Pharmaceuticals, Cheshire, UK) with oxygen supplementation for a maximum duration of two hours. Subcutaneous buprenorphine hydrochloride (Reckitt \& Colman Products Ltd., UK) was administered to provide up to 24 hours of postoperative analgesia. No hamster required further doses of analgesia in the postoperative period.

Talaporfin sodium was kindly supplied free of charge (Light Sciences Corporation, Snoqualmie, WA, USA) as a green lyophilised powder in $100 \mathrm{mg}$ vials and reconstituted using sterile normal saline to a suitable concentration for hamster use. For drug administration, a laparotomy was performed under sterile conditions to provide access for direct intracaval injection and light delivery. The animals remained in a darkened environment for a total of 48 hours after photosensitisation and were assessed daily.

2.1. Fluorescence Microscopy. The pharmacokinetics of talaporfin were studied using fluorescence microscopy. Hamsters were injected with $5 \mathrm{mg} / \mathrm{kg}$ and killed at time intervals of 15 , $30,60,120$, and 240 minutes and 24 hours after sensitisation ( 2 animals at each time point, including 2 unsensitised animals to measure autofluorescence). At postmortem, samples of liver, duodenum, and pancreas were harvested and snapfrozen by immersion in isopentane (2-methylbutane; $\mathrm{BDH}$, UK) prechilled in liquid nitrogen and stored at $-80^{\circ} \mathrm{C}$. For analysis, the tissue blocks were mounted on OCT medium (tissue tek II embedding compound; $\mathrm{BDH}, \mathrm{UK}$ ) and 4, $10 \mu \mathrm{m}$ thick sections cut from each block using a Cryocut E microtome (Reichert-Jung) and thawed prior to fluorescence microscopy.

Fluorescence was excited by a $1.8 \mathrm{~mW}$ helium-neon laser $(532.8 \mathrm{~nm})$ coupled to a liquid light guide with the beam directed via a band-pass filter at $540 \mathrm{~nm}$ into the dichroic mirror housing for epifluorescence studies (Omega Optical Inc.). Fluorescence was detected between 630 and $690 \mathrm{~nm}$ using a combination of band-pass (Omega Optical Inc.) and long-pass (Schott) filters using an Olympus IMT-2 inverted microscope (10x objective magnification) with epifluorescence and phase-contrast attachments.

Fluorescence was quantified using a highly sensitive, cryogenically cooled CCD (charge-coupled device) camera (Wright Instruments, Model 1, resolution $400 \times 600$ pixels) fitted to the microscope and was processed by an IBM personal computer into a falsely colour-coded image of the tissue sections. Fluorescence was reported in counts per pixel, corrected for autofluorescence (about 30 counts per pixel). Tissue samples were taken from two animals per time point with at least two sections per organ from each animal. Four readings per tissue section were then taken for a minimum of 16 separate fluorescence readings per time point per organ.

2.2. Photodynamic Therapy. The PDT studies were divided into 2 sections - the first to optimise the drug light interval and the second to study the specific effects on the pancreas and the surrounding organs. In both, the hamsters were sensitised by an intracaval injection of talaporfin at laparotomy and light from a $664 \mathrm{~nm}$ laser (IRIS Medical OcuLight 664) delivered using a $400 \mu \mathrm{m}$ diameter, cleaved optical fibre placed perpendicular to and touching the surface of the targeted organ. There was no shielding of surrounding organs and light scatter with illumination through and beyond the directly targeted organs was observed. The laser power output from the fibre tip was set at $100 \mathrm{~mW}$ using a power meter (Model TPM-300, Gentec Electro-Optics Inc., Qc, Canada).

2.3. Drug Light Interval (DLI). Studies to establish the drug light interval for maximum PDT effect were undertaken on the liver using a talaporfin dose of $5 \mathrm{mg} / \mathrm{kg}$ and a light dose of $50 \mathrm{~J}$, the interval between drug administration and light delivery being varied from 5 to 240 minutes ( 2 animals at each DLI). After light delivery, the laparotomy wound was closed and the animal was killed 3 days later. At postmortem, the dimensions of the near spherical zone of PDT necrosis in the liver were measured in three axes and the volume of necrosis was calculated: $V=4 / 3 \pi \cdot a \cdot b \cdot c$ (where $a, b$, and $c$ $=$ perpendicular axes of necrosis in $\mathrm{mm}$ ). This study showed that the optimum drug light interval was 15 minutes, so this value was used in the subsequent safety studies.

2.4. Safety Study. The main purpose of the study was to establish the safety of talaporfin PDT for treatment of pancreatic cancer, so this part of the work was to examine the effect of delivering light directly to the pancreas and the immediately adjacent organs that might be at risk. In addition to the work in the pancreas, the organs specifically targeted were the liver, spleen, duodenum, and retroperitoneum (major blood vessels), with most studies being undertaken targeting the pancreas with increasing drug and light doses. The resources available made it unrealistic to treat each target organ under all the conditions under consideration, so only selected values 
TABLE 1: Summary of treatment response of individual hamsters in the safety study.

\begin{tabular}{|c|c|c|c|c|}
\hline Target organ & Drug dose $(\mathrm{mg} / \mathrm{kg})$ & Light dose $(\mathrm{J})$ & Day of cull & Comment \\
\hline \multirow{6}{*}{ Liver } & 1 & 50 & 3 & Macroscopic lesion \\
\hline & 1 & 50 & 3 & Macroscopic lesion, adhesion to colon \\
\hline & 1 & 50 & 21 & Small superficial lesion, adhesion to colon \\
\hline & 1 & 50 & 21 & Small superficial lesion \\
\hline & 5 & 50 & 3 & Large lesion with adhesion to stomach \\
\hline & 5 & 50 & 3 & Large lesion with adjacent duodenal injury \\
\hline \multirow{10}{*}{ Pancreas } & 1 & 20 & 3 & Minimal erythema \\
\hline & 1 & 20 & 3 & No definite effect \\
\hline & 5 & 20 & 3 & $\begin{array}{l}\text { No lesion in pancreas. Adhesions and full thickness gastric } \\
\text { lesion }\end{array}$ \\
\hline & 1 & 20 & 21 & No lesions \\
\hline & 1 & 20 & 21 & No lesions \\
\hline & 1 & 25 & 21 & No lesion in pancreas. Adhesion to liver \\
\hline & 5 & 20 & 21 & No lesion in pancreas. Scar in stomach \\
\hline & 5 & 20 & 21 & No lesion in pancreas. Scar in stomach \\
\hline & 5 & 50 & 12 (>10\% weight loss) & $\begin{array}{l}\text { Lesion in pancreas, multiple adhesions, ascites, small } \\
\text { bowel perforation }\end{array}$ \\
\hline & 5 & 50 & 13 (>10\% weight loss) & $\begin{array}{l}\text { Lesion in pancreas, multiple adhesions, small and large } \\
\text { bowel perforation }\end{array}$ \\
\hline \multirow{2}{*}{ Duodenum } & 2 & 15 & 3 & Sealed perforation, adhesions \\
\hline & 2 & 20 & 3 & Sealed perforation, adhesions \\
\hline \multirow{2}{*}{ Spleen } & 1 & 20 & 3 & Small lesion, minor bowel adhesion \\
\hline & 1 & 20 & 3 & Small lesion and subcapsular haematoma \\
\hline \multirow{2}{*}{ Aorta } & 2 & 15 & 3 & No lesions seen \\
\hline & 2 & 15 & 3 & No lesions seen \\
\hline
\end{tabular}

of the drug and light doses were studied. This approach was felt to be justified as the value of the whole study was essentially to compare the safety of talaporfin PDT with that of PDT in these organs with other photosensitisers, as has been reported in many earlier publications from this and other centres. The actual treatment parameters studied are shown in Table 1.

After treatment and recovery, the hamsters were killed at 2 different time points. The first group was culled at 72 to 96 hours, known to be the best time interval to ascertain the maximum extent of PDT tissue injury (Day 3 group). Hamsters in the second group were allowed to recover for 21 days as a survival study and were then culled to establish whether the healing of PDT-treated areas was satisfactory in terms of structural integrity and function of organs (Day 21 group). Any animal that had lost more than $10 \%$ of its pretreatment weight prior to the scheduled day for culling was killed immediately, in accordance with the care of laboratory animals guidelines. The effects of PDT were documented at postmortem. Apart from the liver, the treated organs were too small for accurate quantification of the extent of necrosis, so the results were limited to macroscopic assessment for evidence of necrosis, perforation, leakage of blood, bile or gastrointestinal contents, gastric or duodenal ulceration, and ascites.
The pancreas, free edge of lesser omentum, duodenum, stomach, aorta, vena cava, bile duct, and liver were removed at necropsy if macroscopic lesions were evident, or if these were the targeted tissue sites, regardless of obvious PDT lesions. Tissue was preserved in formalin and processed for wax block sectioning and haematoxylin-eosin staining for histological analysis. One unsensitised animal was treated with $100 \mathrm{~J}$ of light at $100 \mathrm{~mW}$ targeted at the pancreas to exclude a thermal laser effect. Another received $5 \mathrm{mg} / \mathrm{kg}$ talaporfin without light activation to exclude any dark toxicity.

\section{Results}

3.1. Fluorescence Microscopy. The results are shown in Figure 1. The highest drug concentrations were seen in the liver with the peak at one hour. Intermediate levels were seen in the duodenum and with the lowest values being documented in the pancreas. In the pancreas and duodenum, peak levels were seen after 15 minutes with a second slightly lower peak at 2 hours, after which the concentration fell in all 3 organs.

3.2. Drug Light Interval (DLI). Full thickness liver lobe lesions (3-5 $\mathrm{mm}$ thickness) were seen at all DLI measurements up to 4 hours. The lesions were well demarcated and 


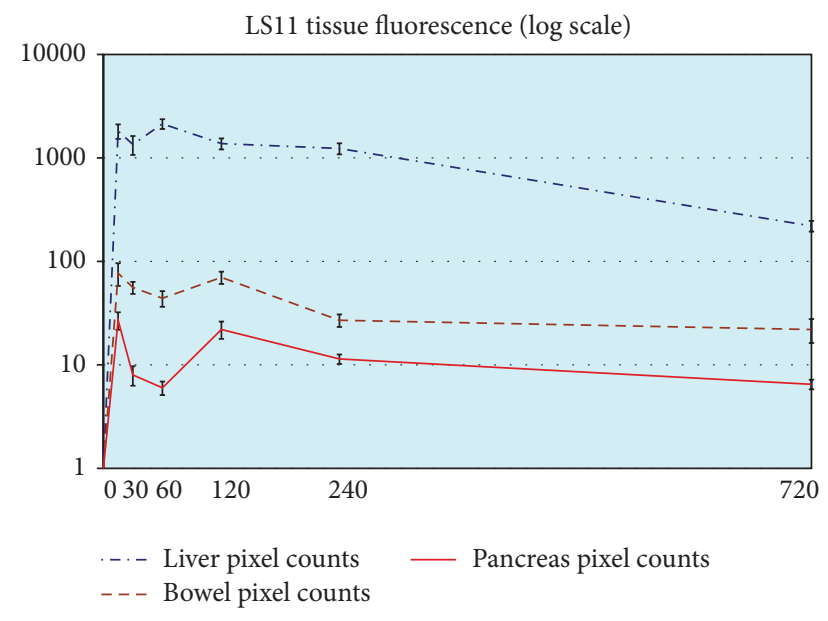

FIGURE 1: Fluorescence (in counts per pixel \pm SD as a log scale, corrected for autofluorescence) measured in cryosections of liver, duodenum, and pancreas as a function of the time after administration of $5 \mathrm{mg} / \mathrm{kg}$ talaporfin.

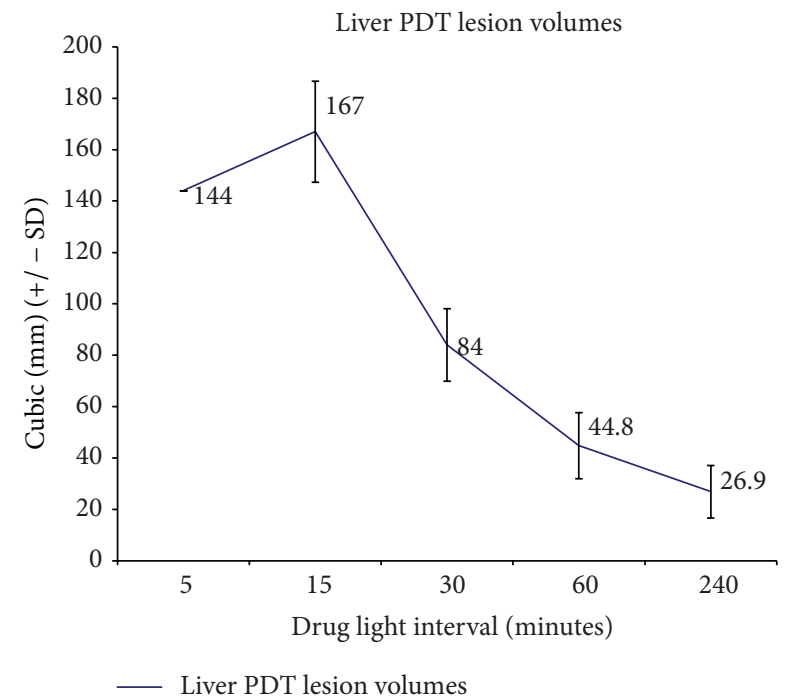

FIgURE 2: Volume of PDT necrosis in liver from hamsters treated with $50 \mathrm{~J}$ red light $(664 \mathrm{~nm})$ as a function of time after administration of $5 \mathrm{mg} / \mathrm{kg}$ talaporfin.

roughly spherical in shape. The volume of necrosis as a function of the DLI is shown in Figure 2. The greatest volume of necrosis was observed with a 15 minute DLI $\left(167 \mathrm{~mm}^{3}\right.$ $\left(n=3\right.$; SD $\left.\left.19.7 \mathrm{~mm}^{3}\right)\right)$ and this interval was therefore chosen for the subsequent safety studies. Lesions at longer intervals became progressively smaller.

3.3. Safety Study. All animals in the safety study were treated with a DLI of 15 minutes. The results for individual animals are summarised in Table 1. No lesions were seen in the control animals treated with drug alone or light alone.

3.3.1. General Morbidity. All animals lost some weight initially, up to $5 \%$ of baseline body weight, indicating a degree of physical harm as a result of the laparotomy and PDT treatment, compared to the control animals having laparotomy and drug alone or light alone. Recovery, including regaining lost weight, was universal by 21 days post-PDT in all but the two hamsters which received high dose pancreatic PDT who were culled prematurely for severe complications.

3.3.2. Liver. Four animals in the Day 3 group (including 2 from the DLI study) and two in the Day 21 group underwent PDT of the middle or left liver lobes with a 15 -minute DLI. Those treated with the highest doses of drug $(5 \mathrm{mg} / \mathrm{kg})$ and light (50 J) showed macroscopic PDT lesions with adhesions to adjacent stomach, small bowel, or colon. A section of treated liver is shown in Figure 3(a). Those treated under less severe conditions, including the two hamsters in the Day 21 group, showed similar, but milder effects. There were no fatal complications and no evidence of biliary obstruction or gallbladder injury.

3.3.3. Pancreas. Ten animals underwent PDT with light applied directly to the pancreas and a DLI of 15 minutes. Three were culled on day 3 and 7 on day 21 . With a light dose of 20 $25 \mathrm{~J}$, no pancreatic lesions were seen with a drug dose up to the maximum of $5 \mathrm{mg} / \mathrm{kg}$. However, some of these animals showed lesions in adjacent organs. Full thickness gastric lesions, but without evidence of perforation, were seen in one animal culled on day 3 and in 2 culled on day 21 (all treated with $5 \mathrm{mg} / \mathrm{kg}, 20 \mathrm{~J}$ ). Adhesions were noted in 1 of 3 animals culled on day 3 post-PDT and in 1 of 5 animals in the group culled on day 21 . There was no evidence of biliary obstruction at light doses of up to $25 \mathrm{~J}$. Significant pancreatic lesions were seen in 2 animals treated with $50 \mathrm{~J}$ and $5 \mathrm{mg} / \mathrm{kg}$. These animals were culled at 12 and 13 days due to more than $10 \%$ weight loss. At necropsy there was macroscopic evidence of duodenal perforation, full thickness gastric lesions, and peritonitis with extensive local adhesions to liver, stomach, small bowel, and colon in both. A histological section showing the junction of normal and PDT-treated pancreas is shown in Figure 3(b).

3.3.4. Duodenum. The most severe damage was seen with duodenal treatment. Two animals treated with the low doses of $2 \mathrm{mg} / \mathrm{kg}$ and $15-20 \mathrm{~J}$ showed full thickness lesions with sealed perforations and adhesions to adjacent liver and colon.

3.3.5. Spleen. Two animals in the Day 3 group had splenic PDT at $1 \mathrm{mg} / \mathrm{kg}$ and $20 \mathrm{~J}$. There was localised puckering and scarring at the site of PDT and one animal had histological evidence of a subcapsular haematoma, but with no evidence of clinical distress.

3.3.6. Aorta and IVC. No definite PDT lesions were found macroscopically or on histology in two animals treated with PDT at $2 \mathrm{mg} / \mathrm{kg}$ and $15 \mathrm{~J}$, when the laser fibre was used to directly target the exposed vessels.

The severity of scarring and adhesions increased with the severity of the treatment conditions (drug and light doses), as expected. Moderate adhesions were observed between PDT-treated liver and bowel, and PDT-treated pancreas and 


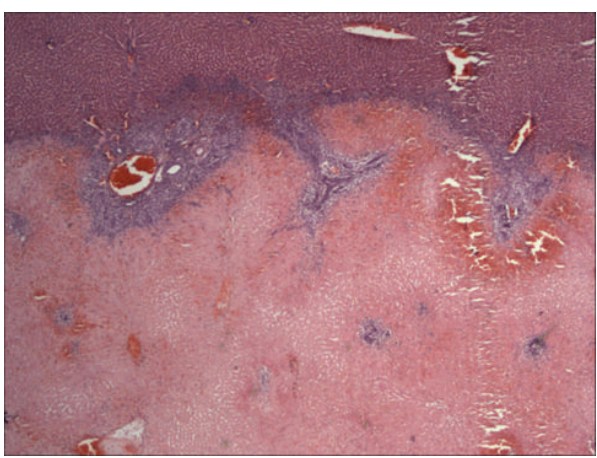

(a)

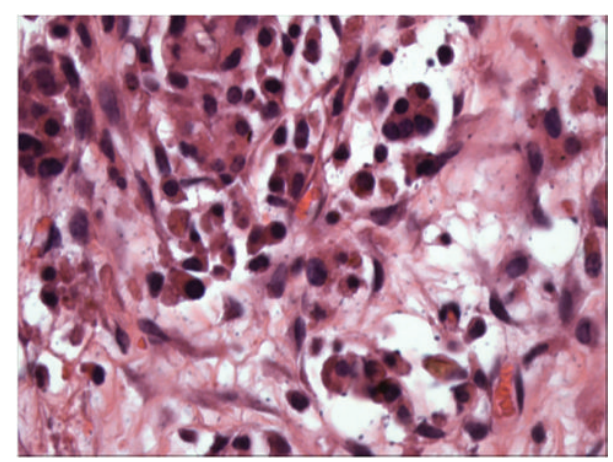

(b)

FIGURE 3: (a) Histological section of liver 3 days after treatment with PDT showing the sharp demarcation between PDT necrosis and untreated liver with a few islands of viable tissue in the necrotic area. (b) Histological section of pancreas 12 days after treatment demonstrating the junction of normal pancreas (top left) with PDT necrosis (bottom right).

bowel. In the maximally treated animals, adhesions were more extensive and were seen in multiple areas between the pancreas, liver, and intestinal tract.

\section{Discussion}

Destroying a cancer of localised and known extent with PDT is relatively straightforward. A key issue is what happens where the cancer meets normal tissue and how the treated area heals. The aim of this study was to establish if talaporfin PDT is safe for the treatment of pancreatic adenocarcinoma. Previous hamster studies have looked at the effect of PDT with mTHPC, with which the optimum drug light interval is up to 4 days for treating cancers of the pancreas [19]. In this work, treating normal pancreas was shown to be safe, but the duodenum was found to be vulnerable under conditions required for cancer therapy [22]. These hamster results were borne out in our clinical study with mTHPC [17]. The present study shows that the most effective DLI for talaporfin is 15 minutes, at which time the drug is predominantly in the vasculature, so different effects might be anticipated. It is of interest to note that the highest concentration of drug in the liver measured by fluorescence was at one hour, whereas the volume of necrosis was nearly 4 times greater at 15 minutes than it was at one hour, suggesting that the drug is more effective if it remains in the vasculature. Nevertheless, our results show that PDT with talaporfin is remarkably similar to that seen with mTHPC. In the liver, quite large areas of necrosis can be produced, but these heal safely and without sequelae.

One of the major attractions of PDT is that there is no significant change in tissue temperature during treatment, so connective tissues like collagen are largely unaffected [25]. This helps to maintain the mechanical integrity of tissue, particularly hollow organs. However, if the conditions used for treating a cancer cause serious damage to the normal tissue in which the cancer arose or adjacent normal tissues, then the treatment may be detrimental. For this reason, it is essential to understand what PDT does to a normal organ before using it to treat a cancer in that organ. In the case of the pancreas, the risks are that PDT might cause a fistula or lead to duct obstruction with consequent pancreatitis and also that it might seriously injure adjacent tissues like the duodenum. The pancreas, however, seems relatively resistant and lesions can only be produced with high drug $(5 \mathrm{mg} / \mathrm{kg})$ and light $(50 \mathrm{~J})$ doses. These lesions heal safely, but light scattered from the pancreas under these conditions causes overwhelming damage to adjacent organs. Perforations to the large and small intestine were seen, together with full thickness lesions in the stomach wall, ascites, and multiple adhesions. Preservation of collagen in the gastric wall probably explained why the stomach was less prone to perforation than the thinner-walled duodenum but, fortunately, there was no evidence of biliary tree or vascular injury.

These results help to define how PDT with talaporfin might safely be used for cancers of the pancreas in humans. The red light used in this study $(664 \mathrm{~nm})$ produced effects up to 6-8 mm deep in tissue. Due to the smaller scale of the hamster pancreas, it is not unexpected that a significant amount of light directed at the head of the pancreas was scattered to the duodenum. However, in humans, the distances are much greater, so that as long as the light delivery fibre is separated from the duodenum by more than about $1 \mathrm{~cm}$ (for example by positioning the fibre tip $1 \mathrm{~cm}$ deep into the pancreatic tissue), duodenal damage is unlikely, as shown in the clinical studies with mTHPC.

Previous work has also looked at the effect of PDT with mTHPC on cancers of pancreatic origin transplanted into the hamster pancreas [19]. The present study did not extend to looking at the effects on transplanted cancers, as our aim was to establish safety. Skin photosensitivity was also not assessed in the present study, but other publications have shown that this is a maximum of 1-2 weeks for talaporfin [18].

In patients, talaporfin doses of $2 \mathrm{mg} / \mathrm{kg}$ or $40 \mathrm{mg} / \mathrm{m}^{2}$ have been used safely in Phase I and II studies of solid tumours $[18,21]$. The light dose delivered determines the size of the PDT lesion, so that larger tumour masses can be treated using multiple laser fibres or with sequential fibre placement within a treatment window of 15 minutes to 1 hour after injection of photosensitiser. Waiting for longer periods of up to 
4 hours, as shown in Figure 2, to allow talaporfin to distribute into the extracellular matrix, did not seem advantageous in this study, as fluorescence data showed no increase in talaporfin tissue levels than earlier time periods and PDT lesions seen in the liver were smaller than at 15 minutes. These results are comparable to those reported for another short acting photosensitiser, verteporfin, in both experimental and clinical studies $[26,27]$.

It is concluded that the results of the current work, together with other published experimental and clinical data, support the use of talaporfin in Phase 1 studies of PDT for pancreatic cancer in inoperable patients with localised disease, although care must be taken to minimise the exposure of the duodenum to light.

\section{Abbreviations}

mTHPC: Meso-tetrahydroxyphenyl chlorin

PDT: Photodynamic therapy

DLI: Drug light interval.

\section{Conflict of Interests}

The authors declare that there is no conflict of interests regarding the publication of this paper.

\section{Acknowledgments}

This work was supported by NIH grant P01 CA084203 and the UCLH/UCL Comprehensive Biomedical Centre which receives a proportion of funding from the Department of Health's National Institute for Health Research (NIHR) Biomedical Research Centres funding scheme. None of these organisations were involved in the statistical analysis, interpretation of the results or the writing of this article.

\section{References}

[1] A. Jemal, A. Thomas, T. Murray, and M. Thun, "Cancer statistics, 2002," CA-A Cancer Journal for Clinicians, vol. 52, no. 1, pp. 2347, 2002.

[2] D. M. Parkin, P. Pisani, and J. Ferlay, "Global cancer statistics," CA-A Cancer Journal for Clinicians, vol. 49, no. 1, pp. 33-64, 1999.

[3] T. J. Kinsella, Y. Seo, J. Willis et al., "The impact of resection margin status and postoperative CA19-9 levels on survival and patterns of recurrence after postoperative high-dose radiotherapy with 5-FU-based concurrent chemotherapy for resectable pancreatic cancer," The American Journal of Clinical Oncology, vol. 31, no. 5, pp. 446-453, 2008.

[4] G. Eeson, N. Chang, C. E. McGahan et al., "Determination of factors predictive of outcome for patients undergoing a pancreaticoduodenectomy of pancreatic head ductal adenocarcinomas," $H P B$, vol. 14, no. 5, pp. 310-316, 2012.

[5] O. Turrini, F. Paye, P. Bachellier et al., "Pancreatectomy for adenocarcinoma in elderly patients: postoperative outcomes and long term results: a study of the French Surgical Association," European Journal of Surgical Oncology, vol. 39, no. 2, pp. 171-178, 2013.
[6] J. He, B. H. Edil, J. L. Cameron et al., "Young patients undergoing resection of pancreatic cancer fare better than their older counterparts," Journal of Gastrointestinal Surgery, vol. 17, no. 2, pp. 339-344, 2013.

[7] H. A. Burris III, M. J. Moore, J. Andersen et al., "Improvements in survival and clinical benefit with gemcitabine as firstline therapy for patients with advanced pancreas cancer: a randomized trial," Journal of Clinical Oncology, vol. 15, no. 6, pp. 2403-2413, 1997.

[8] T. Conroy, F. Desseigne, M. Ychou et al., "FOLFIRINOX versus gemcitabine for metastatic pancreatic cancer," New England Journal of Medicine, vol. 364, no. 19, pp. 1817-1825, 2011.

[9] B. Glimelius, K. Hoffman, P.-O. Sjödén et al., "Chemotherapy improves survival and quality of life in advanced pancreatic and biliary cancer," Annals of Oncology, vol. 7, no. 6, pp. 593-600, 1996.

[10] D. D. Von Hoff, T. Ervin, F. P. Arena et al., "Increased survival in pancreatic cancer with nab-paclitaxel plus gemcitabine," The New England Journal of Medicine, vol. 369, no. 18, pp. 1691-1703, 2013.

[11] R. H. Hawes, Q. Xiong, I. Waxman, K. J. Chang, D. B. Evans, and J. L. Abbruzzese, "A multispecialty approach to the diagnosis and management of pancreatic cancer," The American Journal of Gastroenterology, vol. 95, no. 1, pp. 17-31, 2000.

[12] M. Sant, C. Allemani, M. Santaquilani, A. Knijn, F. Marchesi, and R. Capocaccia, "EUROCARE-4. Survival of cancer patients diagnosed in 1995-1999. Results and commentary," European Journal of Cancer, vol. 45, no. 6, pp. 931-991, 2009.

[13] T. Kuroda, T. Kumagi, T. Yokota et al., "Improvement of longterm outcomes in pancreatic cancer and its associated factors within the gemcitabine era: a collaborative retrospective multicenter clinical review of 1, 082 patients," BMC Gastroenterology, vol. 13, article 134, 2013.

[14] J. Luo, L. Xiao, C. Wu, Y. Zheng, and N. Zhao, “The incidence and survival rate of population-based pancreatic cancer patients: shanghai cancer registry 2004-2009," PLoS ONE, vol. 8, no. 10, Article ID e76052, 2013.

[15] Z. Gong, E. A. Holly, and P. M. Bracci, "Survival in populationbased pancreatic cancer patients: San Francisco Bay Area, 19951999," The American Journal of Epidemiology, vol. 174, no. 12, pp. 1373-1381, 2011.

[16] D. P. Cronin-Fenton, R. Erichsen, F. V. Mortensen, S. Dikinis, M. Nørgaard, and J. Jacobsen, "Pancreatic cancer survival in central and northern Denmark from 1998 through 2009: a population based cohort study," Clinical Epidemiology, vol. 3, supplement 1, pp. 19-25, 2011.

[17] S. G. Bown, A. W. R. Hatfield, A. Z. Rogowska et al., "Photodynamic therapy for cancer of the pancreas," Gut, vol. 50, no. 4 , pp. 549-557, 2002.

[18] R. A. Lustig, T. J. Vogl, D. Fromm et al., "A multicenter phase I safety study of intratumoral photoactivation of talaporfin sodium in patients with refractory solid tumors," Cancer, vol. 98, no. 8, pp. 1767-1771, 2003.

[19] P. Mlkvy, H. Messman, A. J. MacRobert et al., "Photodynamic therapy of a transplanted pancreatic cancer model using metatetrahydroxyphenylchlorin (mTHPC)," British Journal of Cancer, vol. 76, no. 6, pp. 713-718, 1997.

[20] J. Usuda, H. Tsutsui, H. Honda et al., "Photodynamic therapy for lung cancers based on novel photodynamic diagnosis using talaporfin sodium (NPe6) and autofluorescence bronchoscopy," Lung Cancer, vol. 58, no. 3, pp. 317-323, 2007. 
[21] M. Kujundžić, T. J. Vogl, D. Stimac et al., "A phase II safety and effect on time to tumor progression study of intratumoral light infusion technology using talaporfin sodium in patients with metastatic colorectal cancer," Journal of Surgical Oncology, vol. 96, no. 6, pp. 518-524, 2007.

[22] P. Mlkvy, H. Messmann, M. Pauer et al., "Distribution and photodynamic effects of meso-tetrahydroxyphenylclhlorin (mTHPC) in the pancreas and adjacent tissues in the Syrian golden hamster," British Journal of Cancer, vol. 73, no. 12, pp. 1473-1479, 1996.

[23] J. Regula, B. Ravi, J. Bedwell, A. J. MacRobert, and S. G. Bown, "Photodynamic therapy using 5 -aminolaevulinic acid for experimental pancreatic cance-Prolonged animal survival," British Journal of Cancer, vol. 70, no. 2, pp. 248-254, 1994.

[24] T. Schroder, I.-W. Chen, M. Sperling, R. H. Bell Jr., K. Brackett, and S. N. Joffe, "Hematoporphyrin derivative uptake and photodynamic therapy in pancreatic carcinoma," Journal of Surgical Oncology, vol. 38, no. 1, pp. 4-9, 1988.

[25] H. Barr, C. J. Tralau, P. B. Boulos, A. J. MacRobert, R. Tilly, and S. G. Bown, "The contrasting mechanisms of colonic collagen damage between photodynamic therapy and thermal injury," Photochemistry and Photobiology, vol. 46, no. 5, pp. 795-800, 1987.

[26] L. Ayaru, J. Wittmann, A. J. MacRobert, M. Novelli, S. G. Bown, and S. P. Pereira, "Photodynamic therapy using verteporfin photosensitization in the pancreas and surrounding tissues in the Syrian golden hamster," Pancreatology, vol. 7, no. 1, pp. 2027, 2007.

[27] M. T. Huggett, M. Jermyn, A. Gillams et al., "Phase I/II study of verteporfinphotodynamic therapy in locally advanced pancreatic cancer," British Journal of Cancer. In press. 

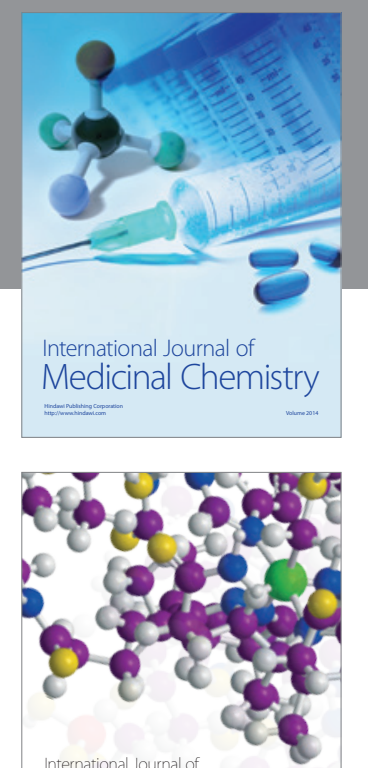

\section{Carbohydrate} Chemistry

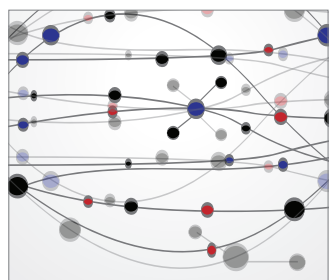

The Scientific World Journal
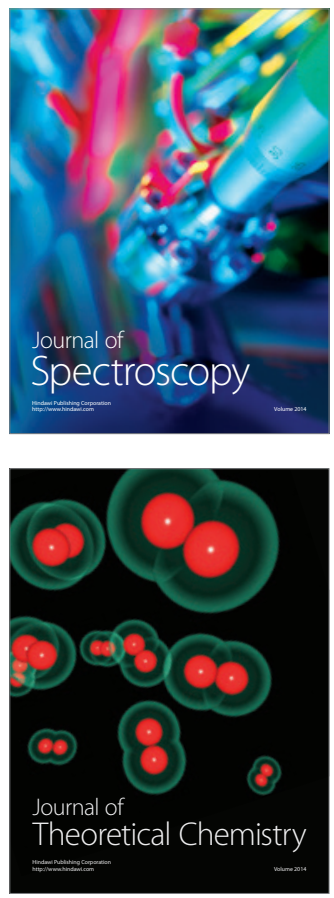
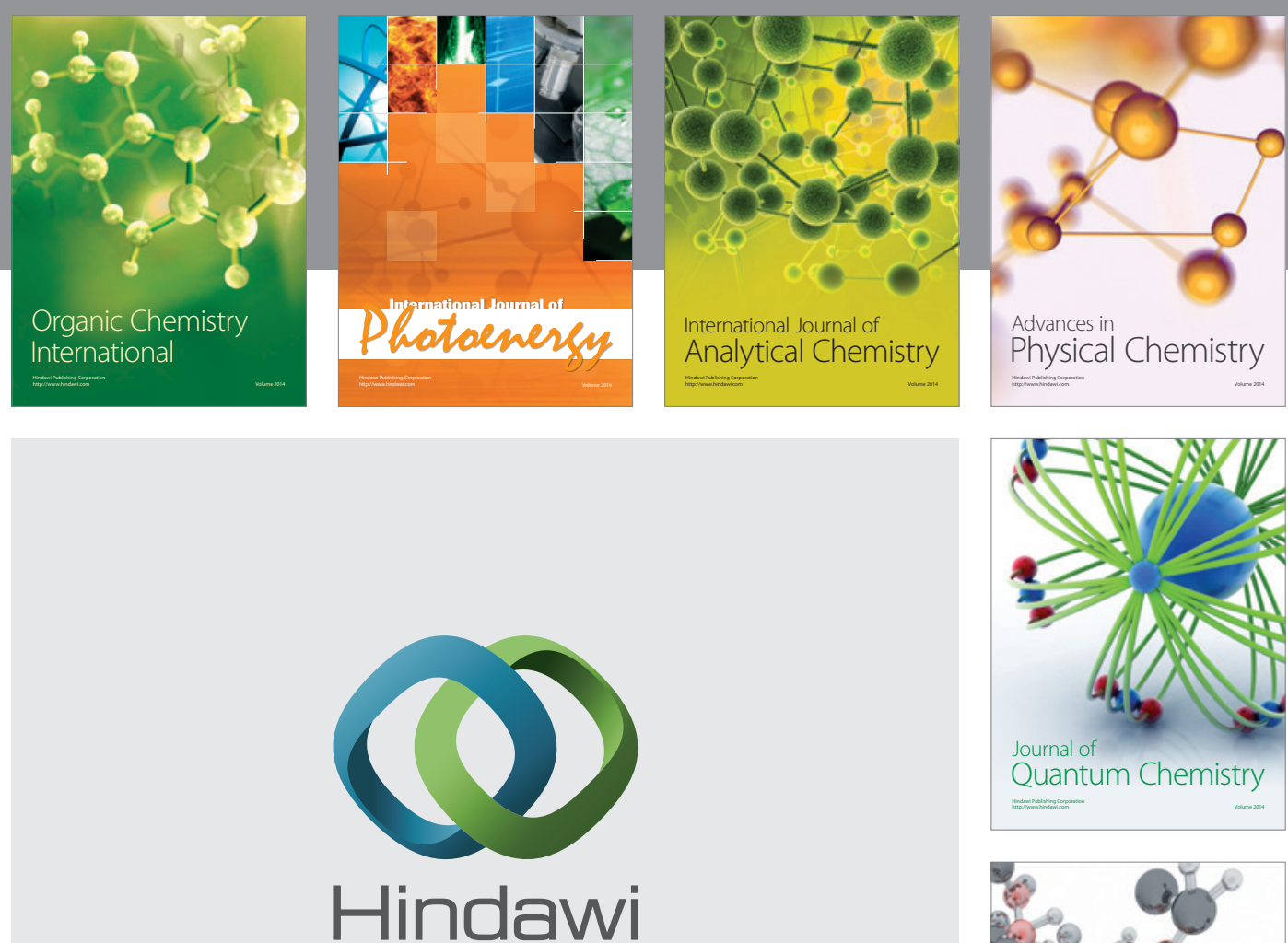

Submit your manuscripts at

http://www.hindawi.com

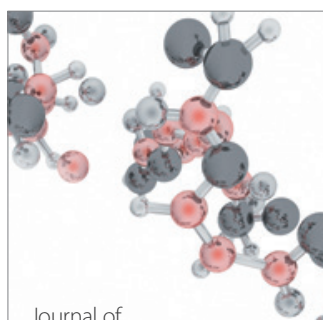

Analytical Methods

in Chemistry

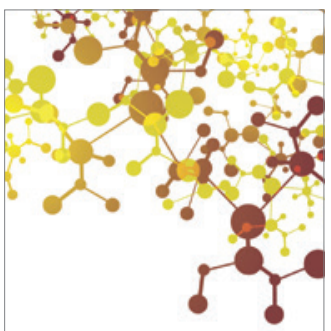

Journal of

Applied Chemistry

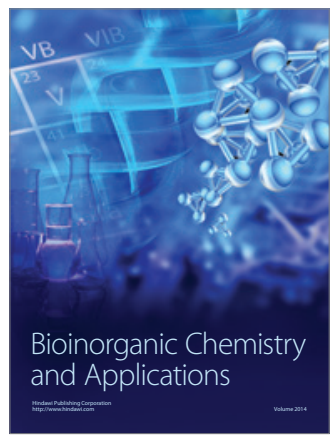

Inorganic Chemistry
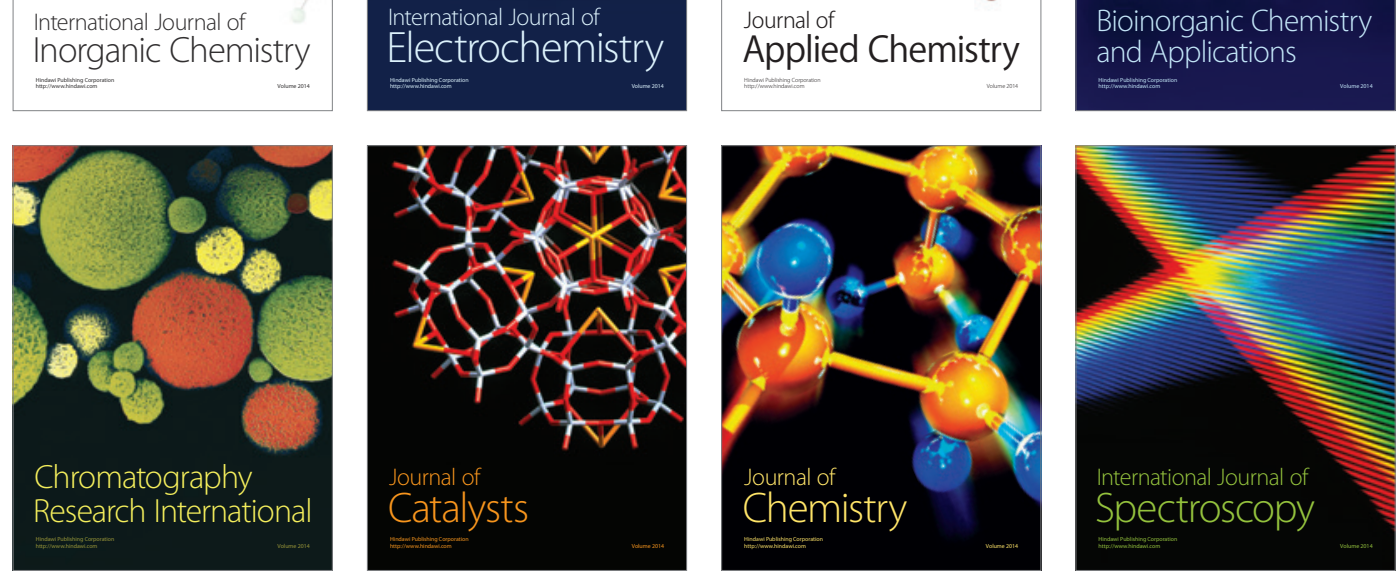